\title{
Percepção de Educação Ambiental nas escolas e a ideia de bem viver
}

\author{
Perception of Environmental Education in school and the idea of well \\ Percepción de la Educación Ambiental en las escuelas y la idea de una
}

Recebido: 26/02/2021 | revisado: 04/03/2021 | aceito: 09/03/2021 | publicado: 17/03/2021

\author{
Marlanda Patrícia Caure da Cunha \\ ORCID: https://orcid.org/0000-0002-9279-6960 \\ Universidade Regional do Noroeste do Estado do Rio Grande do Sul, Brasil \\ E-mail: marlanda.cunha@sou.unijui.edu.br \\ Cleusa Adriane Menegassi Bianchi \\ ORCID: https://orcid.org/0000-0003-2016-9412 \\ Universidade Regional do Noroeste do Estado do Rio Grande do Sul, Brasil \\ E-mail: cleusa.bianchi@unijui.edu.br \\ Daniel Rubens Cenci \\ ORCID: https://orcid.org/0000-0001-7919-6840 \\ Universidade Regional do Noroeste do Estado do Rio Grande do Sul, Brasil \\ E-mail: danielr@unijui.edu.br
}

\begin{abstract}
Resumo
A educação ambiental desenvolvida a partir de objetivos básicos, visando alcançar o bem viver, possibilita a construção de uma sociedade mais responsável e preparada para lidar com adversidades existentes tanto na área econômica, social e ambiental. Desse modo, através de pesquisas bibliográficas em artigos científicos e literaturas referentes ao presente tema, serão relatadas algumas ações socioeducativas desenvolvidas no ambiente escolar, com o objetivo de identificar e apresentar possíveis soluções para os atuais problemas presentes na sociedade. Do mesmo modo, pretende-se que este estudo sirva de parâmetro para o surgimento de novas ideias e ações inovadoras referentes à educação ambiental nas escolas. A pesquisa contempla o método de investigação descritivo, bibliográfico, explicativo, bem como, será feita uma abordagem metodológica qualitativa, com a finalidade de identificar no contexto do ambiente escolar a efetivação da proposta de bem viver, como um meio de articulação e discussão, capaz de promover a sustentabilidade a partir de uma educação ambiental de qualidade nas escolas.
\end{abstract}

Palavras-chave: Bem viver; Educação ambiental; Sustentabilidade.

\begin{abstract}
Environmental education developed based on basic objectives, aiming to achieve the well-living, enables the construction of a society that is more responsible and prepared to deal with the existing adversities, both in the economic, social and environmental areas. Thus, through bibliographic research in scientific articles and literature related to this theme, some socio-educational actions developed in the school environment will be reported, with the objective of identifying and presenting possible solutions to the current problems present in society. Likewise, this study is intended to serve as a parameter for the emergence of new ideas and innovative actions related to environmental education in schools. The research includes descriptive, bibliographic and explanatory research methods, as well as a qualitative methodological approach, with the purpose of identifying the implementation of the proposal of well-living in the school environment, as a means of articulation and discussion, capable of promoting sustainability from a quality environmental education in schools.
\end{abstract}

Keywords: Well-living; Environmental education; Sustainability.

\section{Resumen}

La educación ambiental desarrollada en base a objetivos básicos, con el fin de lograr el buen vivir, permite construir una sociedad más responsable y preparada para enfrentar las adversidades existentes en los ámbitos económico, social y ambiental. Así, a través de la investigación bibliográfica sobre artículos científicos y literatura referente a la presente temática, se reportarán algunas acciones socioeducativas desarrolladas en el ámbito escolar, con el objetivo de identificar y presentar posibles soluciones a los problemas actuales presentes en la sociedad. Asimismo, se pretende que este estudio sirva como parámetro para el surgimiento de nuevas ideas y acciones innovadoras en materia de educación ambiental en las escuelas. La investigación contempla el método de investigación descriptiva, bibliográfica, explicativa, así con un abordaje metodológico cualitativo, con el propósito de identificar en el contexto del ámbito escolar la realización de la propuesta del buen vivir, como medio de articulación y discusión, capaz de promover la sostenibilidad basada en una educación ambiental de calidad en las escuelas.

Palabras clave: Buen vivir; Educación ambiental; Sustentabilidad. 


\section{Introdução}

A educação ambiental no ambiente escolar é o um dos meios que oportuniza o pensamento crítico responsável, preparando o indivíduo para a construção de ideias inovadoras capazes de gerar mudanças positivas na sociedade.

Em contrapartida ao "modelo de desenvolvimento econômico vigente", voltado apenas à prevalência do lucro e aumento do capital, a educação ambiental permite uma visão mais ampla dos problemas existentes na sociedade, a qual leva em consideração "valores éticos, de justiça social e solidariedade", sendo totalmente distinta do atual sistema capitalista que se faz presente (Maria Pelicioni \& Arlindo Phillipi, 2005, p. 3).

Nesse sentido, cabe destacar que os principais problemas ambientais existentes decorrem de um profundo colapso que se instalou no mundo, diante de padrões de consumo insustentáveis ocasionados a partir da evolução tecnológica das indústrias, crescimento demográfico acelerado, trazendo como consequência a degradação de recursos naturais.

Certamente, a "deterioração do meio ambiente e da sociedade afetam de modo especial os mais frágeis do planeta". Facilmente é possível de se observar tal realidade no dia-a-dia, além de pesquisas científicas que classificam os pobres, como os mais desfavorecidos, diante dos atuais paradigmas da sociedade (Papa Francisco, 2015, p. 38).

Com relação às "alterações ambientais, estas se tornam visíveis e produzem mudanças indesejáveis, tais como: alterações climáticas, extinção de espécies e de diversidade de ecossistemas, poluição, escassez de água potável, erosão cultural e outras" (Genebaldo Dias, 2004 p. 15).

A partir disso, é importante entender as consequências que esses problemas ambientais causaram no planeta:

A problemática ambiental abriu um processo de transformação do conhecimento, expondo a necessidade de gerar um método para pensar de forma integrada e multivalente os problemas globais e complexos, assim como a articulação de processos de diferente ordem de materialidade. Deste modo, o conceito de ambiente penetra nas esferas da consciência e do conhecimento, no campo da ação política e na construção de uma nova economia, inscrevendo-se nas grandes mudanças do nosso tempo (Henrique Leff, 2012, p. 56).

Frente a essa realidade, o estilo de vida das pessoas é fator determinante para o controle e proteção dos recursos ambientais, sendo essencial o convívio em sociedade a partir da ideia do bem viver, compreendido este como a forma "de conduzir a vida em plenitude, consistindo em uma relação de equilíbrio com a natureza" (Saulo Rodrigues \& Eveline Rodrigues, 2015, p. 218).

Nesse sentido, partindo da ideia de compreender melhor as relações humanas e o meio ambiente, colabora o entendimento de Capra (1996, p. 25) apud Mariotto \& Caraiola, (2009, p. 241): "A ecologia profunda não separa seres humanos - ou qualquer outra coisa do meio ambiente natural. Ela vê o mundo não como uma coleção de objetos isolados, mas como uma rede de fenômenos que estão profundamente interconectados e são interdependentes".

Sendo assim, construir ações socioeducativas de forma comprometida, interligadas aos princípios básicos da Educação Ambiental (EA), possibilita articulações importantes, aproxima o homem da natureza, possibilita uma relação de racionalidade e respeito e ameniza os conflitos sociais, econômicos e, principalmente, ambientais.

A educação é um dos alicerces da sociedade, tanto que compõe um dos Objetivos do Desenvolvimento Sustentável. Desse modo, partindo do entendimento que a Educação Ambiental é indispensável para o desenvolvimento da humanidade, torna-se relevante explicitar os benefícios que ela poderá agregar, dentre eles, "proporcionar aos cidadãos os conhecimentos científicos e tecnológicos e as qualidades morais necessárias que lhes permitam desempenhar um papel efetivo na preparação e no manejo de processo de desenvolvimento" (Genebaldo Dias, 2004, p. 149).

Importante salientar que a Educação Ambiental foi inserida no Brasil pela lei federal n 9.795 de 27 de abril de 1999, sendo oficializada através da lei federal nº.938 de 1981, que criou a Política Nacional do Meio Ambiente (PNMA). A EA representa avanço e conquista para todos os brasileiros, pois a partir deste marco histórico, tornou-se essencial e componente 
permanente, devendo estar presente de "forma articulada, em todos os níveis e modalidades do processo educativo, em caráter formal e não-formal” (Brasil, 1999).

Somente é possível definir Educação Ambiental levando em consideração uma nova dimensão de ensino, adaptada à realidade interdisciplinar de temas ambientais locais e globais. Esse novo enfoque busca a consciência crítica que permita o entendimento e a intervenção de todos os setores da sociedade, encorajando o surgimento de um novo modelo de sociedade (Silva, Barbosa \&Araújo, 2018).

Seguindo nesse mesmo entendimento, "o aspecto político da educação ambiental envolve o campo da autonomia, da cidadania e da justiça social, cuja importância as transforma em metas que não podem ser conquistadas num futuro distante, mas devem ser construídas no cotidiano das relações afetivas, educacionais e sociais” (Philippi \& Pelicioni, 2005, p.406).

Sendo assim, é preciso cada vez mais se pensar na construção de estratégias socioeducativas sólidas na sociedade, capazes de surtir efeito de sensibilização nos indivíduos. "Se a pessoa é sensibilizada, ela valoriza o que está sendo degradado ou ameaçado de degradação" (Genebaldo Dias, 2004, p. 125).

Partindo desse entendimento, esta revisão pretende analisar ações de EA desenvolvidas em três escolas municipais de ensino fundamental, pertencentes a diferentes regiões do Brasil, relatadas em artigos científicos. A partir da análise destas ações, propor futuras estratégias, no âmbito escolar, conforme será mencionado a seguir.

\section{Metodologia}

Cabe destacar que para realizar este estudo foram feitas pesquisas em artigos, teses e revistas científicas, afim de identificar as principais ações referentes a Educação Ambiental que estão sendo realizadas nas escolas, capazes de promover a percepção do que seria a EA a partir da ideia de bem viver, o que caracteriza o método bibliográfico da pesquisa.

Quanto aos demais métodos utilizados, o descritivo e o qualitativo, importante frisar que na pesquisa descritiva os "fatos são observados, registrados, analisados, classificados e interpretados, sem interferência do pesquisador. Bem como há o uso de técnicas padronizadas de coleta de dados (questionário e observação sistemática)" (William Rodrigues, 2007).

No que diz respeito a pesquisa qualitativa, colabora o entendimento na qual "os métodos qualitativos são aqueles nos quais é importante a interpretação por parte do pesquisador com suas opiniões sobre o fenômeno em estudo" (Pereira A.S. et al. (2018).

Sendo assim, torna-se necessário relatar brevemente as instituições envolvidas neste trabalho. A primeira escola pesquisada está localizada na cidade de Manaus, a qual no ano de 2013 realizou a coleta de dados dos alunos no $7^{\circ}$ ano, através de questionário, com questões de múltipla escolha, com o objetivo de quantificar os problemas ambientais existentes.

A segunda instituição trata-se da escola municipal de ensino João Pessoa-Tupanói, localizada na cidade de São Sepé/RS, em que alunos dos $6^{\circ}$ e $7^{\circ}$ ano responderam questionários e posteriormente foram propostas ações referentes à Educação Ambiental.

A outra instituição envolvida nesta pesquisa é a Escola Municipal João XXIII, localizada no bairro Iputinga, na cidade de Recife/PE, que a partir de abordagem qualitativa por meio de entrevistas, aplicação de questionário e realização de oficinas, permitiu analisar se as estratégias realizadas na escola estavam contribuindo para a formação de sujeitos ecológicos.

Todavia, o estudo será feito utilizando fontes bibliográficas, a fim de identificar o papel das escolas brasileiras com ênfase às instituições atuantes na promoção da sustentabilidade a partir de abordagens sobre a Educação Ambiental.

\section{Resultados e Discussão}

Inicialmente se faz necessário reconhecer a importância da Educação Ambiental para a sociedade, principalmente a forma em que ela está sendo desenvolvida neste espaço de troca de saberes e aprendizagem. Sendo assim, é relevante 
compreender de que forma ocorre a formação do saber ambiental, que contribui para a existência de jovens e cidadãos mais críticos e comprometidos com a realidade que se faz presente.

Com base nesse entendimento, colabora significativamente a seguinte ideia:

A construção de uma racionalidade ambiental implica a formação de um novo saber a integração interdisciplinar do conhecimento, para explicar o comportamento de sistemas socioambientais complexos. O saber ambiental problematiza o conhecimento fragmentado em disciplinas e a administração setorial do desenvolvimento, para construir um campo de conhecimentos teóricos e práticos orientado para a articulação das relações sociedade-natureza (Leff, 2012, p.145).

Nesse sentido, cabe destacar as questões éticas que envolvem a Educação Ambiental, sendo estas indispensáveis na construção de um saber crítico e comprometido com a sociedade, conforme o entendimento a seguir:

No ano de 1949, já falava em estabelecer uma "Ética" nas nossas relações com a natureza. O seu trabalho viria a gerar a "Carta da Terra" durante a Rio-92. Aqui se faz um chamamento para as responsabilidades individuais, isto é, ao final do dia você, como indivíduo, deverá ter dado uma resposta, uma contribuição efetiva para esse novo estilo de vida. Trata-se de uma questão de responsabilidade(...) (Genebaldo Dias, 2004, p. 103).

Frente a tais questões éticas e diante do atual cenário de degradação dos recursos naturais, os pobres são os povos mais desfavorecidos. "A população de baixa renda tem vivido diretamente os impactos dos problemas ambientais. Tal fato acaba por aumentar suas dificuldades cotidianas, expressas pela falta de água, de energia, de espaços habitacionais seguros, de alimentação, entre outros" (Philippi \& Pelicioni, 2005, p. 7).

Certamente a população precisa reconstruir as relações sociais, com base em princípios de ética, justiça e sustentabilidade. Isso somente se torna possível a partir da elaboração de estratégias embasadas em novos paradigmas, permitindo o reconhecimento da responsabilidade individual de cada um, a mudança de pensamento, a discussão das causas dos problemas ambientais, sendo o papel da Educação Ambiental indispensável neste processo civilizatório.

A identificação e realização de ações referentes ao meio ambiente no espaço das escolas, são de suma importância, possibilitando uma visão mais ampla para os alunos, educadores e demais envolvidos nas instituições e na sociedade, o que pode ser evidenciado nos exemplos citados a seguir.

A primeira pesquisa realizada, abrange 7 escolas Municipais de Manaus, envolvendo alunos do $7^{\circ}$ ano do ensino fundamental. O estudo aconteceu a partir de questionários auto administrados, por meio dos quais ocorreu a coleta de dados, investigando os participantes no ambiente escolar. $\mathrm{O}$ instrumento adotado foi um questionário, contemplando questões de múltiplas escolhas, com perguntas fechadas, mas apresentando uma série de possíveis respostas. No total, 171 estudantes responderam ao questionário.

Num primeiro momento, os participantes foram questionados a respeito do que eles consideravam problemas ambientais, possibilitando-lhes a escolha de até três respostas. A grande maioria considerou como problemas ambientais a poluição das águas (90\%), o lixo (49\%), a fumaça de carro (46\%) e esgoto a céu aberto (42\%). Já, com menores valores percentuais, a contaminação do solo (31\%), falta de água (16\%), enchentes (16\%), poeira (5\%) e buzina (3\%). Logo veremos na figura a seguir dados estatísticos referentes ao percentual de respostas quanto aos problemas ambientais que os participantes consideraram mais relevantes. 
Figura 1: Percentual de respostas quanto aos problemas ambientais que os participantes consideraram mais relevantes.

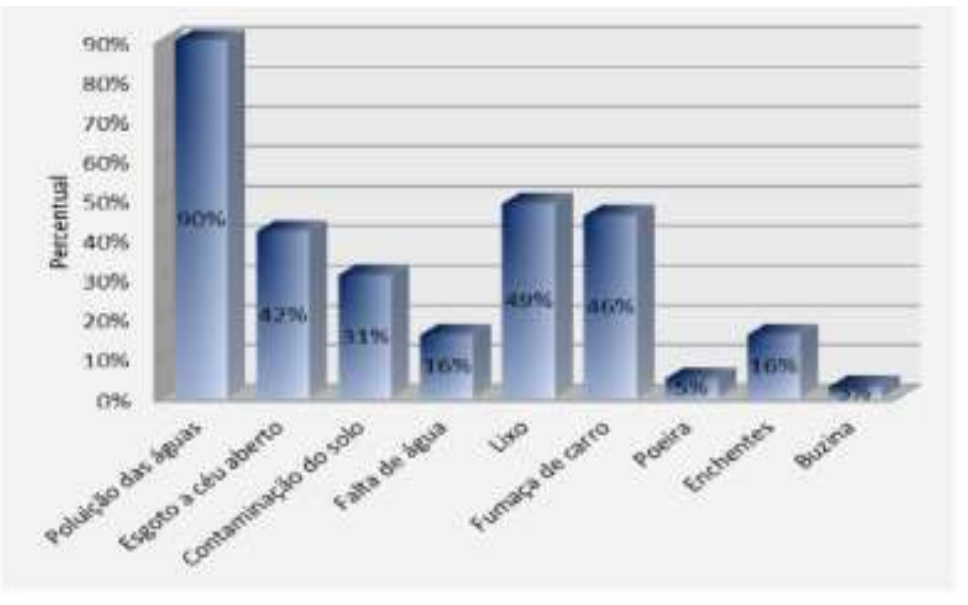

Fonte: França e Guimarães (2019).

Também foram identificadas ações praticadas pelos estudantes para a proteção do meio ambiente. Entre as ações mais desenvolvidas, estão o descarte do lixo em local adequado, evitar o desperdício de água e o cuidado com as plantas e as árvores. A partir das respostas, foi possível observar a importância de desenvolver projetos de coleta seletiva nas escolas, uma vez que a maioria da população desconhece as principais etapas para o gerenciamento correto dos resíduos: "a não geração, a redução, a reutilização, a reciclagem, o tratamento e a disposição final dos resíduos", sendo fundamental esse conhecimento a fim de se preservar o meio ambiente como um todo (Brasil, 2010).

Outra parte importante da coleta de dados, refere-se ao questionamento acerca das atividades desenvolvidas sobre a conscientização ambiental, sendo apontada como principal atividade, a realização de palestras, representando 53\% dos respondentes. A reciclagem ficou em segundo plano, representando $40 \%$ das respostas e em terceiro lugar, a coleta seletiva, com 30\%. Ainda sobre o questionário, os alunos foram indagados sobre com que frequência as ações eram desenvolvidas na escola. A maioria, 37\%, responderam que às vezes sua escola promove estas ações.

No entanto, a questão que mais impacta, diz respeito à motivação dos alunos em mudar as atitudes dentro da própria escola, em que cerca de $88 \%$ dos participantes responderam que se sentiam motivados. Isso demonstra um resultado positivo, confirmando a importância das discussões a partir da Educação Ambiental no ambiente escolar.

A segunda escola que abrange este estudo é a Escola João Pessoa-Tupanói, localizada na zona rural da cidade de São Sepé/RS. A instituição atende cerca de cento e cinquenta e cinco alunos, pertencentes às séries finais do ensino fundamental, do $6^{\circ}$ ao $9^{\circ}$ ano. Fazem parte do quadro de recursos humanos, dezoito professores, todos com curso superior e sete funcionários.

A escola tem como missão, "valorizar o homem do meio rural, a família, o trabalho, o conhecimento e cultura, buscando através, seu aprimoramento e desenvolvimento para que possa ter melhor qualidade de vida no campo, ou condições de avançar no estudo, exercendo assim a sua cidadania” (Adriana Bolzan, 2011, p. 31).

Diante desta perspectiva da instituição, foi iniciada uma Proposta Pedagógica no ano de 2010, com o objetivo de pesquisar qual o nível de informação dos alunos a respeito da arborização na escola e o meio ambiente em geral. Para isso, foi aplicado um questionário para identificar o grau de conhecimento dos estudantes sobre o assunto.

Com a finalidade de possibilitar melhor compreensão do que se pretendia a partir desse projeto, foram transmitidos vídeos na escola, momento em que foram feitas observações sobre a importância do cuidado com os animais e em preservar a natureza e demais seres vivos. 
Para dar continuidade ao projeto, foi realizada uma pesquisa junto aos órgãos responsáveis, que são a Associação RioGrandense de Empreendimentos de Assistência Técnica e Extensão Rural (EMATER) e a Secretaria de Agricultura de São Sepé. A pretensão era levantar quais espécies de árvores se adaptam melhor no local. A partir desse levantamento, foi proposto o plantio de mudas de árvores, como uma atividade prática, permitindo o compartilhamento e integração com o meio ambiente, promovendo a conscientização para um meio ambiente mais arborizado.

A terceira e última escola pesquisada, que pertence à Rede Municipal da cidade do Recife (PE), é a Escola João VIII, a qual faz parte do projeto COM-VIDA, que tem como proposta realizar ações voltadas a melhorias do Meio Ambiente e da qualidade de vida, promovendo o intercâmbio entre escola e comunidade.

Os objetivos a serem desenvolvidos nas escolas mediante essa nova organização (COM-VIDA), são os seguintes:

$\checkmark$ Desenvolver e acompanhar a EA na escola de forma permanente;

$\checkmark$ Ajudar a cuidar do Brasil, assumindo como orientação a Carta das Responsabilidades "Vamos Cuidar do Brasil";

$\checkmark$ Fazer a Agenda 21 na escola;

Diante destes princípios, foi realizado o levantamento de dados na Escola João VIII, utilizando-se dos seguintes instrumentos: observação, entrevista, aplicação de questionário e realização de oficinas. O questionário foi composto por cinco perguntas com a finalidade de identificar a percepção de EA nas estratégias da COM-VIDA.

A partir dos resultados do questionário, observados na Figura 2, verificou-se que 25\% dos estudantes veem a EA como uma maneira de conservação/preservação do Meio Ambiente; $25 \%$ conceituou a EA como uma forma de melhorar o Meio Ambiente, $25 \%$ não souberam dizer o que era a EA, como fica claro nesta fala: "Ainda não sei sobre isso" (estudante 1), e $25 \%$ generalizaram o conceito, como percebido nesta manifestação "são tantas coisas" (estudante 4). Desse modo, a figura a seguir representa estatisticamente os percentuais a respeito da Concepção de Educação Ambiental, ou seja, qual a percepção dos estudantes sobre a importância da EA.

Figura 2: Concepção de Educação Ambiental.

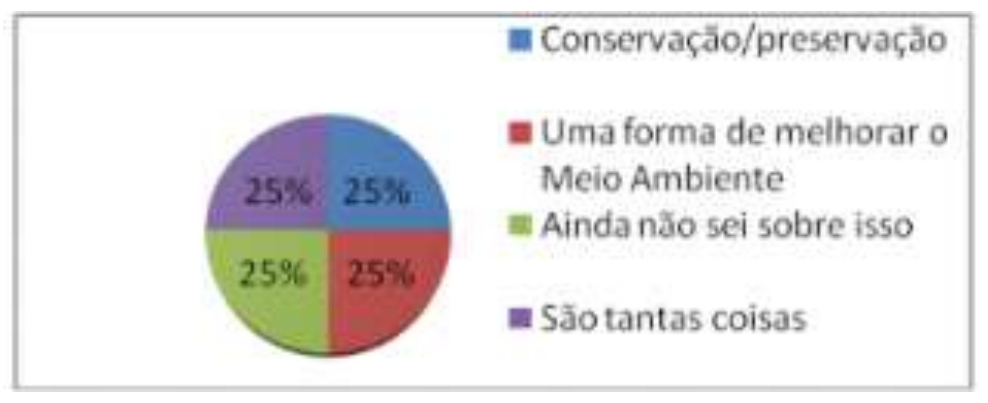

Fonte: Camboim e Barbosa (2012).

Foram desenvolvidas atividades práticas na escola, entre elas, a visita ao Jardim Botânico, a oficina mini feira e a oficina concurso de desenho. Os estudantes foram questionados posteriormente sobre qual das ações gostaram mais. Sobre este tópico, 50 \% dos estudantes responderam que foi a ida ao Jardim Botânico, 25\% a mini feira, e 25\% o concurso do desenho.

A realização de oficina como o concurso de desenhos permite trabalhar vários aspectos do comportamento e das habilidades dos estudantes. Para os psicólogos pode ser uma ferramenta para compreender melhor a personalidade da criança, o seu lado emocional, bem como demonstrar o que eles estão sentindo. É uma forma de reconhecer e descobrir o talento dos estudantes. Todavia, é importante que os concursos não provoquem apenas o aspecto da competição, que é uma de suas perspectivas, alimentando uma rivalidade nos estudantes. Competição e cooperação são processos sociológicos que podem ser habilmente trabalhados por meio de oficinas dessa natureza (Camboim \& Barbosa, 2012, p. 132). 
O desenvolvimento dessas atividades teóricas e práticas na Escola João VIII, possibilitaram a compreensão de conceitos distintos que envolvem a EA. A partir da realização da oficina de desenho, os estudantes puderam entender a diferença, por exemplo, entre "reciclagem" e "reutilização", uma vez que num primeiro momento, ambos os conceitos tinham a mesma significância para os estudantes.

\section{Considerações Finais}

A partir das pesquisas bibliográficas realizadas, referentes ao estudo de caso das escolas que desenvolvem ações de Educação Ambiental, foi possível constatar que apesar dessas instituições apresentarem características estruturais distintas, ambas atuam com foco na mesma pretensão. Promover estratégias com base em princípios na qual permitam articulações das relações sociedade-natureza.

Entretanto, apesar da evolução e o envolvimento de muitas escolas na perspectiva de inserirem temáticas referentes à Educação Ambiental, observam-se ainda enormes desafios para o desenvolvimento acerca deste tema, principalmente partindo da existência de burocratização nos processos pedagógicos atuais.

É preciso fortalecer cada vez mais as ações de Educação Ambiental que já vêm sendo desenvolvidas no ambiente escolar, de maneira comprometida, abrangendo todos os entes vinculados às instituições, permitindo a ampliação de ideia inovadoras, a construção de estratégias interdisciplinares, voltadas para uma abordagem ampla de conceitos que envolvam o meio ambiente e a sociedade de modo geral.

Buscar o aprofundamento da Educação Ambiental, localmente e globalmente, é uma tarefa árdua que demanda esforços conjuntos. No entanto, quando desenvolvida com qualidade, baseada em princípios básicos, tais como ética, justiça e sustentabilidade, pode acarretar resultados transformadores e significativos, impactando positivamente as relações ecológicas atuais.

Certamente a ideia de bem viver aliada a princípios basilares da Educação Ambiental, podem trazer retorno ainda melhores, como, por exemplo, promover relações com mais equilíbrio entre o homem e a natureza. Uma formação ambiental de qualidade, somente será possível mediante a flexibilização quanto a resistências teóricas e pedagógicas ainda existentes nas escolas, permitindo a transformação dos atuais paradigmas e a continuidade de projetos apoiadores de ações ambientais nas mais diversas instituições educacionais existentes, capazes de promover a sustentabilidade e a construção de uma sociedade mais responsável e preocupada com as questões ecológicas.

Sendo assim, destaca-se a importância na continuidade de estudos como este, capazes de agregarem novas experiências aos profissionais e interessados na área da Educação Ambiental. Desse modo, experiências inovadoras que são realizadas por diversos educadores e ainda não divulgadas podem contribuir para a melhoria da educação de cunho ambiental nas escolas, atuando estas na mudança do pensamento e possibilitando a formação de sujeitos mais comprometidos e responsáveis com o meio ambiente e a sociedade como um todo.

\section{Referências}

Bolzan, A. (2011). Ações de Educação Ambiental na escola municipal de ensino fundamental João Pessoa- São Sepé, RS. https://repositorio.ufsm.br/bitstream/handle/1/13726/TCCE_EA_EaD_2011_BOLZAN_ADRIANA.pdf?sequence=1\&isAllowed=y .

Brasil (1999). Lei da Política Nacional de Educação Ambiental, Lei no 9.975, de 27 de abril de 1999. Brasília: Senado Federal.

Brasil. (2010). PNRS/ Política Nacional dos Resíduos Sólidos. LEI 12.305/10. Brasília: Senado Federal.

Camboim, J. F. F. \& Barbosa, A. G. (2020). Estratégias de Educação Ambiental por meio da atuação da COM-VIDA: vivências em uma escola do Recife-PE. https://www.redalyc.org/pdf/4815/481549264010.pdf.

Capra, F. (1996). A teia da vida: Uma nova compreensão científica dos sistemas vivos. http://bibliotecadigital.puc-campinas.edu.br/services/ebooks/Fritjof\%20Capra-1.pdf. 
Research, Society and Development, v. 10, n. 3, e31710313355, 2021

(CC BY 4.0) | ISSN 2525-3409 | DOI: http://dx.doi.org/10.33448/rsd-v10i3.13355

Dias, G. (2004). Educação Ambiental, princípios e práticas, (9a ed.), ed. Gaia.

Dias, J. (2018). Levantamento avalia desafios para metas da ONU em Saúde. Portal Fiocruz. https://portal.fiocruz.br/noticia/levantamento-avalia-desafiospara-metas-da-onu-em-saude.

Francisco, P. (2015). Laudato Si: carta encíclica sobre o cuidado da casa comum, ed. Paulinas.

França, P. \& Guimarães, M. (2014). A educação ambiental nas Escolas Municipais de Manaus (AM): um estudo de caso a partir da percepção dos discentes. Revista Monografias Ambientais, 3128 - 3138, https://dx.doi.org/10.5902/2236130812020.

Leff, H. (2012). Saber ambiental, (9a ed.), ed. Vozes Ltda.

Luft, H., \& Falkembach, E. (2013). Freire na agenda da educação: Educação Ambiental e Outros Autores, ed. Unijuí.

Mariotto, S. \& Caraiola, M. (2009). Educação Ambiental na concepção do pensamento sistêmico. Revista Acadêmica ciência animal, 7(2), 237-243, http://dx.doi.org/10.7213/cienciaanimal.v7i2.9933.

Pereira A. S. et al. (2018). Metodologia da pesquisa científica. UFSM. https://repositorio.ufsm.br/bitstrea m/handle/1/15824/Lic_Computacao_MetodologiaPesquisa-Cientifica.pdf? sequence $=1$.

Philippi, A. \& Pelicioni, M. (2005). Educação Ambiental e Sustentabilidade, ed. Manole Ltda.

Reigota, M. (2017). O que é educação ambiental, ed. Brasiliense, coleção primeiros passos https://books.google.com.br/books?id=gmgvDwAAQBAJ\&printsec=frontcover\&hl=pt-BR\&source=gbs_ge_summary_r\&cad=0\#v=onepage\&q\&f=false.

Rodrigues, S. \& Rodrigues, E. (2015). Direito socioambiental ao bem viver no contexto do constitucionalismo latino-americano: caminhos para o redimensionamento da ideia de dignidade e para a proteção da vida em geral. Revista Juris- 24: 209-230. https://periodicos.furg.br/juris/article/view/6338/4048.

Rodrigues, W. (2007). Metodologia Científica. Trabalho científico UFRGS. https://hugoribeiro.com.br/bibliotecadigital/Rodrigues_metodologia_cientifica.pdf.

Silva, F., Barbosa, M. \& Araújo, K. (2018). Educação ambiental como instrumento de promoção de desenvolvimento e sustentabilidade no contexto do semiárido brasileiro. Instituto o Direito por um planeta verde, vol. I- Conferencistas e Teses de Profissionais. http://www.planetaverde.org/arquivos/biblioteca/arquivo_20180702143948_7222.pdf. 